\title{
Male Mating History in Antheraea mylitta and its Effect on Ejaculation Size and Female Reproductive Fitness
}

\author{
Sudhansu Sekhar Rath* \\ Central Tasar Research \& Training Institute, Piska Nagri, Ranchi-835 303, Jharkhand, India
}

(Received 11 February 2011; Accepted 16 May 2011)

Reproductive activity in the economically important insect, Antheraea mylitta is very important because the female reproduces only once in her life time and the aging is very rapid and costly. It is a capital breeder and strictly a monoandrous species. To know how strategically the insect behaves and the male allocates its ejaculate resource more prudently during its successive mating with virgin females to maximize its own fitness and the fitness of the female with whom it mated, both being most important to sericulture industry. So, the present study was undertaken and the results revealed fresh and virgin females always prefer to mate with fresh virgin males $(84 \%)$ and receives high dose of ejaculates leading to higher hatchability than to virgin males of one day old $(13.7 \%)$ and one day old males with mating experience $(2.3 \%)$. The ejaculation size (as referred to eupyrene sperm count in the ejaculation) declined significantly over successive mating $(r=-0.9931, P<0.001)$, so also the male body weight $(r=-0.9560, P<0.001)$. The quantity of ejaculate passed to female also dramatically declined during aging $(r=-0.9982, P<0.001)$. It was found that male weight contribute substantially to the quantum of ejaculate $(r=-0.9519, P<0.001)$, so also higher fecund females receive relatively more ejaculate than the lower group to reach higher reproductive fitness. The life time fecundity was found to be $334 \pm 31$.

Key words: Antheraea mylitta, Mating history, Ejaculation size, Reproductive fitness

\footnotetext{
*To whom the correspondence addressed

Basic Seed Multiplication and Training Centre, Central Silk Board,P.O. Kerai, Sundargarh-770073, Odisha, India.

Tel \& Fax: +919040480065;

E-mail: ssrathlee@rediffmail.com, ssrathlee_csb@hotmail.com
}

\section{Introduction}

The fact that male contribute substantially to reproduction as female does was become very clear from studies carried out in the past (Boggs, 1990; Gwynne, 1984; Vahed, 1998). Ejaculates serve to maximize the male fitness in several ways (Gillott, 2003), the primary function being to ensure male fertility. Males allocate its sperm in a most adaptive way among ejaculate when it mate more than once (Cook and Wedell, 1996) and in some species males are able to vary the number of sperms ejaculated according to circumstance. Male mating with large females ejaculated more spermatozoa than when mating with small females (Engqvist and Sauer, 2003; Gage, 1998; Gage and Barnard, 1996; Wedell and Cook, 1999). The ejaculate weight decreases over successive matings is very common in insects (Damiens and Boivin, 2006; Eady, 1995; Lauer, 1996; Lewis, 2004; Savalli and Fox, 1999a, b). Many empirical studies have indeed shown that ejaculate allocation patterns are markedly plastic within species (Eddy, 1995; Engqvist and Sauer, 2001; Ofuya, 1995; Wedell et al., 2002).

In Antheraea mylitta the aging is rapid and costly as the insect is very short-lived, and the female reproduce only once in their lifetime (Rath, 2000; Rath et al., 1997; Rath et al., 2002, 2007). The aging has an immense effect on reproductive performance in this insect where a decline in mating success, fecundity and fertility with aging was reported (Rath, 2000; Rath et al., 1997; Rath et al., 2002, 2007). Adult moths are sexually ripened at the time of emergence and the act of mating starts 2-3 hrs after the emergence. Females have full complement of eggs and mating does not stimulate egg production; male ejaculates sufficient sperms (2570 - 3500 sperms per one egg; personal communication of the author) during coupling to fertilize the eggs of the female and no re-mating in this insect is observed (Rath et al., 1997, 2007). Thus $A$. mylitta is monoandrous. It is a capital breeder too in the 
absence of adult feeding. Adult of this species do not need to feed to reproduce successfully as reported in other species also (Savalli and Fox, 1999b; Wightman, 1978) and the ejaculate size may therefore affect female fitness to a great extent which ultimately influence the viable egg production in this economically important insect.

The present study was under taken to understand the effect of male mating history on male reproductive fitness (production of fertile sperms and maintenance of ejaculation size) and female reproductive fitness (life time fecundity and hatching) which is largely not studied in the species. This might be helpful in making strategic approach to augment the egg production to meet the ever increasing demand.

\section{Materials and Methods}

\section{Male mating history and ejaculation size}

Male moth of weight range $3.1 \mathrm{~g}$ to $3.3 \mathrm{~g}$ were used in this experiment and the females used were of $6.5 \mathrm{~g}$ to $7.0 \mathrm{~g}$. Male moths soon after eclosion were separated and made three mating groups- repeated mating (same male was used for 4 successive mating with a resting period of $16 \mathrm{hrs}$ between two matings), alternate mating (the same male was used in alternate days, where the resting period was $40 \mathrm{hrs}$ between two successive matings) and single mating (separate male was used but of different ages, day 0 to day 4). The moths were released inside the nylon net enclosure (separate for each mating group) for mating for 8 hrs (Rath et al., 2002). After recording the mating success five mated females were randomly selected from each lot of the mating type for eupyrene sperm count and the rest were kept in the earthen cups for life time fecundity (Rath et al., 1997) and hatching. There were 10 replications each with 100 moths of either sex.

\section{Body weight loss during repeated mating}

Ten number of male moths were weighed 2-3 hrs after eclosion (2.7 to $3.5 \mathrm{~g}$ weight with separate identifying marks for a definite weight) and then released inside a nylon net for mating with fresh females (weighing 6.4 $6.5 \mathrm{~g}$ ) for $8 \mathrm{hrs}$ (Rath et al., 2002). After $8 \mathrm{hrs}$ of mating the mated males were weighed and then rested for $16 \mathrm{hrs}$ and then again released inside the net for its second mating for $8 \mathrm{hrs}$ with fresh females after that the weight of males were noted. Thus, male moths were mated 4 times and after each mating the weight of males was noted.

Correlation between body weight and ejaculation size Fresh male moths of various weights $(2.65 \mathrm{~g}$ to $3.5 \mathrm{~g})$ were mated with fresh females (2- $4 \mathrm{hrs}$ old, fresh weight-
6.4-6.5 g) for 8 hrs to note any variation in the ejaculation size along the weight range of male moth. After the desired period of mating eupyrene sperm estimation in the ejaculate was made.

To find out whether the female weight has any relation to have a larger ejaculate we have performed an experiment where fresh males having particular body weight 3.30 to $3.33 \mathrm{~g}$ were allowed to mate with fresh females of three different body weight ranges $(5.8 \pm 0.158 \mathrm{~g}, 6.53 \pm$ $0.156 \mathrm{~g}$ and $7.34 \pm 0.102 \mathrm{~g}$ ) for a period of $8 \mathrm{hrs}$. There were 10 replications each with 50 moths. Ten females were randomly selected from each body weight range for eupyrene sperm count while other samples were kept for finding out the realized fecundity and fertility.

\section{Female mating preference}

To find out female mating preference we conduct an experiment where 150 fresh females were released in side a nylon net enclosure along with 150 fresh males, 150 virgin males of 1 day old and 150 earlier mated males of 1 day old in the night. Virgin males of 1 day old and earlier mated males of 1 day old were given identifying marks so that it can be easily identified to find out whether it was mated or not. In the morning mating success with respect to different male categories were noted. After required period of mating ( $8 \mathrm{hrs}$ ) mated females were kept for oviposition to find out the realized fecundity and fertility. There were 7 replications.

\section{Eupyrene sperm count}

The sperm preparation was made by opening the spermatheca and bursa copulatrix of a mated female in $1 \mathrm{ml}$ of Belar's saline (Flint and Kressin, 1969; $6 \mathrm{~g} \mathrm{NaCl}, 0.2 \mathrm{~g}$ $\mathrm{KCl}, 0.2 \mathrm{~g} \mathrm{CaCl}_{2}, 0.2 \mathrm{~g} \mathrm{Na}_{2} \mathrm{CO}_{3}$ and water to make 1 liter) which serve as the diluting medium for sperms. After thorough mixing the sperm suspension was loaded to improved Neobaur's chamber to fill the volume $1 / 50 \mathrm{~mm}^{3}$ (5 small squares- 4 at its corner and 1 at the center of the big central square). Sperms are then counted in the above squares.

\section{Statistical Analysis}

The data collected were subjected to one way ANOVA, correlation and regression analysis (Sokal and Rohlf, 1995) to find out the significant differences.

\section{Results and Discussion}

\section{Ejaculate allocation}

Virgin males contribute more ejaculate to females than did once-, twice- or thrice mated males. The ejaculation size 
Table 1. Effect of male mating history on fecundity, hatching and ejaculation size in Antheraea mylitta (Values are mean \pm SD) [Female moth age 0 day (fresh 2-4 hrs old), fresh wt-6.4-6.5 g]

\begin{tabular}{|c|c|c|c|c|c|}
\hline Mating type & Mated on day & Mating No. & Lifetime fecundity & $\begin{array}{c}\text { Hatching } \\
\%\end{array}$ & $\begin{array}{c}\text { Total eupyrene } \\
\text { sperm count }\left(\mathrm{x} 10^{5}\right)\end{array}$ \\
\hline \multirow{4}{*}{$\begin{array}{c}\text { Repeated (same male is } \\
\text { used successively after } \\
\text { a rest of } 16 \mathrm{hrs)} \\
\text { A combine effect of repeated } \\
\text { mating and aging }\end{array}$} & 0 & 1 & $334 \pm 31^{\mathrm{a}}$ & $91.97 \pm 1.91^{\mathrm{a}}$ & $8.553 \pm 0.392^{\mathrm{a}}$ \\
\hline & 1 & 2 & $\begin{array}{l}242 \pm 16^{b} \\
(-27.5 \%)\end{array}$ & $\begin{array}{c}74.73 \pm 4.23^{b} \\
(-18.7 \%)\end{array}$ & $\begin{array}{c}5.521 \pm 0.311^{b} \\
(-35.4 \%)\end{array}$ \\
\hline & 2 & 3 & $\begin{array}{l}211 \pm 14^{\mathrm{c}} \\
(-36.8 \%)\end{array}$ & $\begin{array}{c}48.71 \pm 3.55^{\mathrm{c}} \\
(-47.0 \%)\end{array}$ & $\begin{array}{c}3.416 \pm 0.446^{\mathrm{c}} \\
(-60.1 \%)\end{array}$ \\
\hline & 3 & 4 & $\begin{array}{l}139 \pm 12^{d} \\
(-58.4 \%)\end{array}$ & $\begin{array}{c}7.43 \pm 1.99^{d} \\
(-91.9 \%)\end{array}$ & $\begin{array}{c}1.584 \pm 0.089^{\mathrm{d}} \\
(-81.5 \%)\end{array}$ \\
\hline $\mathrm{r}$ & & & $-0.9840^{*}$ & $-0.9821^{*}$ & $-0.9931^{*}$ \\
\hline \multirow{3}{*}{$\begin{array}{l}\text { Alternate (same male was } \\
\text { used after a rest of } 40 \mathrm{hrs)} \\
\text { A combine effect of repeated } \\
\text { mating and delayed aging }\end{array}$} & 0 & 1 & $334 \pm 31^{\mathrm{a}}$ & $91.97 \pm 1.91^{\mathrm{a}}$ & $8.553 \pm 0.392^{\mathrm{a}}$ \\
\hline & 2 & 2 & $\begin{array}{l}198 \pm 14^{\mathrm{c}} \\
(-40.7 \%)\end{array}$ & $\begin{array}{c}45.43 \pm 1.19^{\mathrm{c}} \\
(-50.6 \%) \\
\end{array}$ & $\begin{array}{c}3.294 \pm 0.350^{\mathrm{c}} \\
(-59.2 \%)\end{array}$ \\
\hline & 4 & 3 & $\begin{array}{l}140 \pm 15^{d} \\
(-58.1 \%)\end{array}$ & $\begin{array}{c}8.43 \pm 1.27^{\mathrm{d}} \\
(-90.8 \%)\end{array}$ & $\begin{array}{c}1.750 \pm 0.385^{\mathrm{d}} \\
(-79.5 \%)\end{array}$ \\
\hline $\mathrm{r}$ & & & $-0.9741^{*}$ & $-0.9978^{*}$ & $-0.9539^{*}$ \\
\hline \multirow{5}{*}{$\begin{array}{c}\text { Single mating } \\
\text { (separate male was used) } \\
\text { Effect of Aging }\end{array}$} & 0 & 1 & $334 \pm 31^{\mathrm{a}}$ & $91.97 \pm 1.91^{\mathrm{a}}$ & $8.553 \pm 0.392^{\mathrm{a}}$ \\
\hline & 1 & 1 & $\begin{array}{l}263 \pm 24^{\mathrm{e}} \\
(-21.2 \%)\end{array}$ & $\begin{array}{c}79.39 \pm 3.37^{\mathrm{e}} \\
(-13.7 \%)\end{array}$ & $\begin{array}{c}6.656 \pm 0.349^{\mathrm{e}} \\
(-22.2 \%)\end{array}$ \\
\hline & 2 & 1 & $\begin{array}{l}189 \pm 18^{c} \\
(-43.4 \%)\end{array}$ & $\begin{array}{c}60.31 \pm 3.05^{\mathrm{f}} \\
(-34.4 \%)\end{array}$ & $\begin{array}{c}5.456 \pm 0.387^{b} \\
(-36.2 \%)\end{array}$ \\
\hline & 3 & 1 & $\begin{array}{l}132 \pm 15^{d} \\
(-60.5 \%)\end{array}$ & $\begin{array}{c}45.56 \pm 5.16^{\mathrm{c}} \\
(-50.5 \%)\end{array}$ & $\begin{array}{c}3.631 \pm 0.456^{\mathrm{c}} \\
(-57.5 \%)\end{array}$ \\
\hline & 4 & 1 & $\begin{array}{c}98 \pm 14^{f} \\
(-70.6 \%)\end{array}$ & $\begin{array}{c}7.86 \pm 1.68^{\mathrm{d}} \\
(-91.4 \%)\end{array}$ & $\begin{array}{c}1.969 \pm 0.304^{\mathrm{d}} \\
(-77.0 \%)\end{array}$ \\
\hline $\mathrm{r}$ & & & $-0.9910^{*}$ & $-0.9766^{*}$ & $-0.9982 *$ \\
\hline
\end{tabular}

Significant differences are indicated by different superscripts (one-way ANOVA at $5 \%$ level)

$* \mathrm{P}<0.001$

amounts to $8.553 \times 10^{5}$ eupyrene sperms during its first mating which declined drastically by $35.4 \%, 60.1 \%$ and $81.5 \%$ during subsequent matings. Thus, out of a total allocation of $19.074 \times 10^{5}$ eupyrene sperms, a major share of $44.8 \%$ were allocated during first mating; and then $28.9 \%$ during $2^{\text {nd }}, 17.9 \%$ during $3^{\text {rd }}$ and only $8.3 \%$ during $4^{\text {th }}$ mating $(\mathrm{r}=-0.9931, \mathrm{P}<0.001)$. When the males used alternatively, the ejaculation size declined to an extent of $59.2 \%$ upon second mating and $79.5 \%$ upon third mating $(\mathrm{r}=-0.9539, \mathrm{P}<0.001)$. The single mating (age-related changes) revealed $22.2 \%$ decline in ejaculation size on day 1 and further declined on day $2(36.2 \%)$, day 3 $(57.5 \%)$ and day 4 (77.0\%). $(\mathrm{r}=-0.9982, \mathrm{P}<0.001)$ (Table 1, Fig. 1). This reduction in ejaculation size might be due to constrains in production rate (Arnqvist and Danielsson, 1999; Moore et al., 2004), or, the variation in female fecundity may affect the evolution of male ejaculate allocation (Reinhold et al., 2002). Ejaculation size

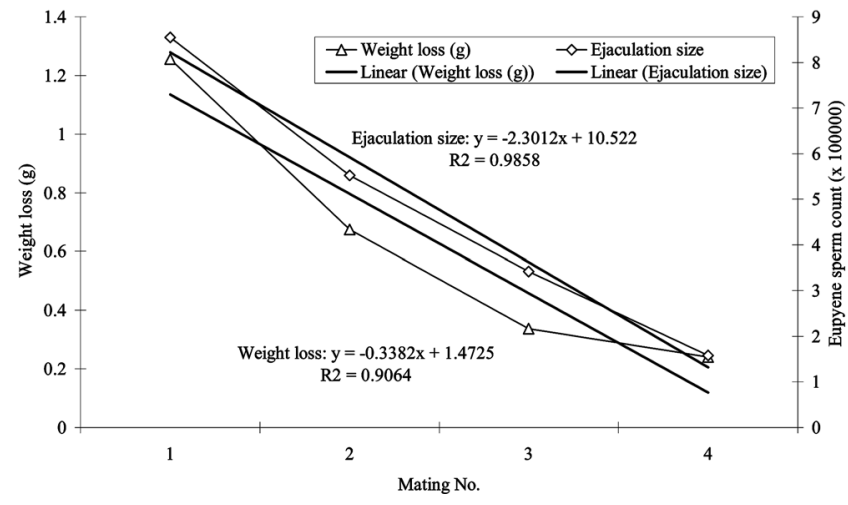

Fig. 1. Relationship of weight loss and total eupyrene sperms ejaculated by male during repeated mating in Antheraea mylitta.

and the number of sperms it contain vary among males (Eady, 1995; Savalli and Fox, 1998) and, within individ- 
Table 2. Female mating preference and its effect on fecundity and fertility in A. mylitta. (Values are mean \pm SD)

\begin{tabular}{cccc}
\hline Details of mating preference & Mating success (\%) & Realized fecundity (nos.) & Hatching \% \\
\hline FF x FM (Fresh females x fresh males) & $84.1 \pm 6.47^{\mathrm{a}}$ & $291 \pm 13^{\mathrm{a}}$ & $92.56 \pm 1.13^{\mathrm{a}}$ \\
\hline FF x VM1 (Fresh females x Virgin males 1 day old) & $13.71 \pm 5.71^{\mathrm{b}}$ & $258 \pm 12^{\mathrm{b}}$ & $86.60 \pm 3.31^{\mathrm{b}}$ \\
\hline FF x MM1 (Fresh females x Mated males 1 day old) & $2.19 \pm 1.79^{\mathrm{c}}$ & $194 \pm 13^{\mathrm{c}}$ & $77.30 \pm 2.27^{\mathrm{c}}$ \\
\hline
\end{tabular}

Significant differences are indicated by different superscripts (one-way ANOVA at $5 \%$ level)

uals, vary with age (Fox et al., 1995a, b) and male mated status as observed in the present investigation. The empirical evidence suggests that male indeed allocate ejaculates according to variation in female fecundity and thus the female body size affects the ejaculation size (Mallard and Barnard, 2003; Simmons et al., 1993; Wedell, 1992). Our results further corroborate the prediction that males are investing more ejaculate in early copulations than the later ones, assuming the probability of achieving additional matings decreases over time (Reinhold et al., 2002). Alternate mating revealed that $A$. mylitta fails to replenish its sperm quantity following a mating where upon $2^{\text {nd }}$ mating the quantity of eupyrene sperms delivered was at par with the quantity of that the male ejaculated during its third repeated mating (Table 1).

Male loses its weight during repeated mating from 3.01 $\mathrm{g}$ to $1.754 \mathrm{~g}$ during its first mating; which further declined to $1.08 \mathrm{~g}, 0.743 \mathrm{~g}$ and $0.502 \mathrm{~g}$ in subsequent mating. Thus, male contributions constituted a substantial proportion of their pre-mating body mass (first mating mean \pm $\mathrm{SD}=41.53 \pm 3.35 \%$; second mating, $22.38 \pm 2.07 \%$; third mating, $11.34 \pm 3.99 \%$ and fourth mating, $7.99 \pm 3.21 \%, r$ $=-0.9560, \mathrm{P}<0.001)$ and the changes between any two mating treatment were found to be significant. There was a close association of weight loss and ejaculation size during repeated mating which revealed that weight loss $(\mathrm{y}=$ $\left.-0.3382 \mathrm{x}+1.4725, \mathrm{R}^{2}=0.9064\right)$ and decline in ejacu-

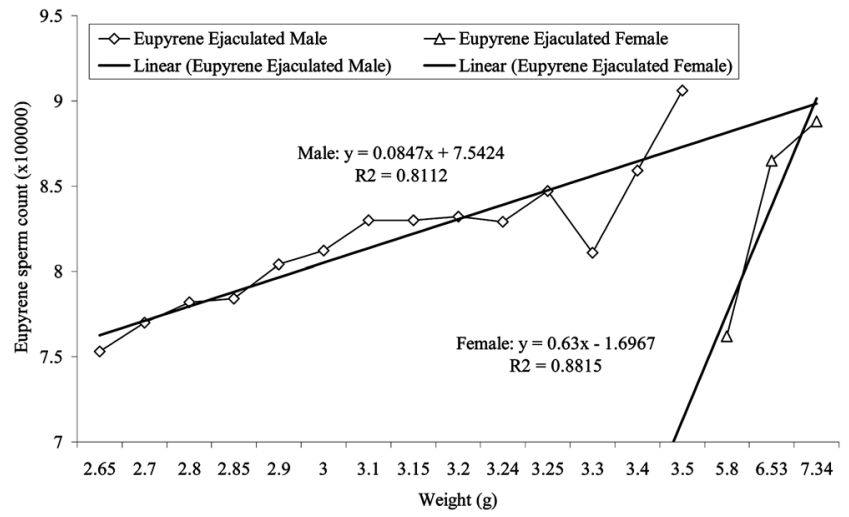

Fig. 2. Effect of body weight on ejaculation size in Antheraea mylitta. lation size $\left(\mathrm{y}=-2.3012 \mathrm{x}+10.522, \mathrm{R}^{2}=0.9858\right)$ was due to repeated mating in A. mylitta (Fig. 1). Earlier findings by Savali and Fox (1999a) and Fischer et al. (2009) reported the loss as a measure of ejaculation size are also in close agreement with our findings.

\section{Male size and sperm number}

There was a positive and significant correlation between male weight and ejaculation size $(y=0.0847 x+7.5424$, $\mathrm{R}^{2}=0.8112$ ), which indicate that male weight contribute $81 \%$ to the ejaculation size (Fig. 2). A positive association between a male size and spermatophore mass that had been reportedly found in butterflies and other insects (Bissoondath and Wiklund, 1996; Karlsson, 1998; Wedell and Cook, 1999; Wiklund and Kaitala, 1995) confirms our findings. Further, this finding corroborates previous finding that spermatophore mass and fertile sperm numbers increased with male size, while non fertile sperm numbers were unrelated to male size (Fischer et al., 2009; Lewis and Wedell, 2007).

\section{Female fitness}

\section{Mating preference}

Fresh females prefer to mate with fresh virgin males $(84 \%)$, than virgin males of one day old $(13.7 \%)$, and one day old males with mating experience $(2.3 \%)$. The realized fecundity and hatching of eggs were also significantly more when fresh females mated with fresh virgin males. Significant differences were observed among the treatment groups in mating success (df 2, 18; F $=531.7729, \mathrm{P}<0.0001)$, realized fecundity ( $\mathrm{df} 2,18$; $\mathrm{F}=103.0297, \mathrm{P}<0.0001)$ and hatching of eggs $(\mathrm{df} 2,18$; $\mathrm{F}=71.5481, \mathrm{P}<0.0001$ (Table 2).

\section{Lifetime fecundity}

The life time fecundity in Antheraea mylitta was recorded to be $334 \pm 31$ and decreased as the male's number of previous matings increased $(r=-0.9840, \mathrm{P}<0.001)$. When males were mated repeatedly with virgin females during aging, their lifetime fecundity was declined by $27.5 \%$, $36.8 \%$ and $58.4 \%$ upon $2^{\text {nd }}, 3^{\text {rd }}$ and $4^{\text {th }}$ mating respectively. In alternate mating, the lifetime fecundity was also declined significantly (by $40.7 \%$ upon $2^{\text {nd }}$ mating and 
Table 3. Relationship between female wt and ejaculation size received. (Values are mean \pm SD)

\begin{tabular}{cccccc}
\hline \multicolumn{2}{c}{ Moth size (wt. in g) } & $\begin{array}{c}\text { Total eupyrene sperms } \\
\left(\times 10^{5}\right) \text { received }\end{array}$ & Realized fecundity & $\begin{array}{c}\text { Hatching \% } \\
\text { (Larvae hatched out) }\end{array}$ & Sperm : egg ratio \\
\hline Male & Female & $7.62 \pm 0.455^{\mathrm{a}}$ & $194 \pm 12^{\mathrm{a}}$ & $\begin{array}{c}82.8 \pm 3.3^{\mathrm{a}} \\
(161)\end{array}$ & $3927: 1$ \\
\hline $3.33 \pm 0.134^{\mathrm{a}}$ & $5.80 \pm 0.158^{\mathrm{a}}$ & $8.65 \pm 0.425^{\mathrm{b}}$ & $282 \pm 9^{\mathrm{b}}$ & $\begin{array}{c}93.2 \pm 2.2^{\mathrm{b}} \\
(263)\end{array}$ & $3067: 1$ \\
\hline $3.30 \pm 0.141^{\mathrm{a}}$ & $6.53 \pm 0.156^{\mathrm{b}}$ & $8.88 \pm 0.450^{\mathrm{b}}$ & $330 \pm 7^{\mathrm{c}}$ & $\begin{array}{c}92.2 \pm 4.3^{\mathrm{c}} \\
(304)\end{array}$ & $2692: 1$ \\
\hline
\end{tabular}

Significant differences are indicated by different superscripts (one-way ANOVA at 5\% level)

$58.1 \%$ during $3^{\text {rd }}$ mating). Single mating revealed that aging alone was responsible for a decline in lifetime fecundity of $21.2 \%, 43.4 \%, 60.5 \%$ and $70.6 \%$ on day 1 , day 2 , day 3 and day 4 respectively $(y=-60.3 \mathrm{x}+323.8$, $\left.\mathrm{F}=164.802, \mathrm{R}^{2}=0.9821, \mathrm{P}<0.001\right)($ Table 1$)$.

\section{Correlation between female weight and ejaculation size}

Heavier females were ejaculated with significantly more sperms by males than the less weighed females, so also the fecundity and fertility were higher in heavier females. Low weighed females $(5.80 \pm 0.158 \mathrm{~g})$ were ejaculated with $7.62 \times 10^{5}$ eupyrene sperms, while the middle weight females $(6.53 \pm 0.156 \mathrm{~g})$ were ejaculated with $13.5 \%$ more $\left(8.65 \times 10^{5}\right.$ eupyrene sperms) and heavier female (7.34 \pm $0.102 \mathrm{~g})$ with $16.5 \%$ more $\left(8.88 \times 10^{5}\right.$ eupyrene sperms $)$. The regression equation $\left(\mathrm{y}=0.63 \mathrm{x}-1.6967, \mathrm{R}^{2}=0.8815\right.$, $\mathrm{P}<0.001)$ revealed female weight contribute $88 \%$ to the ejaculated mass. The realized fecundity was tends to increase significantly in middle weight (by $45.4 \%$ ) and heavier females (by 70.1\%) from 194 in low weighed females. Similarly, the hatching in middle weight and heavier females were significantly higher than the low weight females (Table 3, Fig. 2). The sperm: egg ratio also tends to decline from 3927:1 (in low weighed females) to 3067:1 (in middle weighed group) and 2692:1 in heavy weight group. Such a huge quantity of sperm ejaculation by male in to the body of female might be the reason behind monoandrous nature which ceases the receptivity of the female further in this wild species. Larger ejaculate volumes associated with low degree of polyandry that are reported in bushcricket texa, agrees with our findings (Vahed, 2006).

Earlier reports also revealed that male provided larger females with ejaculates frequently contain more sperm that have increased fecundity in many insects (Engqvist and Suer, 2003; Gage, 1998; Gage and Barnard, 1996; Wedell and Cook, 1999). That at least some male Lepidoptera seem capable of assessing female quality and reproductive potential, and adjust their ejaculate accordingly. Such strategic investment of reproductive sources e.g. by tailoring ejaculates in relation to female size that have been repeatedly documented (Wedell et al., 2002) corroborates our present findings.

Females mated to virgin males had significant higher fecundity than those mated to previously mated males. The lifetime fecundity, hatching and total eupyrene count declines $(\mathrm{P}<0.001)$ as the number of mating increases in repeated mating (where the combine effect of both repeated mating and aging of male moth was observed), so also in alternate mating (where the effect of delayed aging along with repeated mating was seen) and in single mating where the effect of aging of male moth was only observed (Table 1).

Size of the ejaculate plays a significant role in female fitness which generally decreases with the number of times that its mate has mated previously. Decreasing size of the ejaculate has a deep effect on female fitness (Rönn et al., 2008). Female fitness components that were affected by male mating history brings about the changes in ejaculation size and composition over successive matings is the key along with effects on hatching rate of eggs (Rönn et al., 2008) corroborates our findings of the present study.

Our results show that male continue to mate with virgin females even beyond the point $\left(4^{\text {th }}\right.$ in repeated and $3^{\text {rd }}$ in alternate matings) where male ejaculate depletion results in female fitness being compromised. The fecundity of $C$. maculates females was significantly dependent on the male mating history, shown by Ofuya (1995) by mating with males suffering from severe ejaculate depletion, agree with our findings.

The size, quality and number of spermatophore delivered by males have been shown to be highly sensitive to factors like male age at mating, body weight, larval and adult feeding regime, mating order and the time that elapse between consecutive matings (Torres-Vila and Jennions, 2005). Male mating history strongly affects female 
reproductive output in Lepidoptera. Females mated to virgin males had higher fecundities than those mated to previously mated, experienced males (Torres-Vila and Jennions, 2005) further confirms our findings.

The most obvious proximate explanation for the effect of male mating history on female fecundity is that mating history affects spermatophore size as in A. mylitta where the virgin males produced larger number of eupyrene sperms than experienced males. This suggests that lepidopteran males suffer a depletion of spermatophore precursors after each mating.

\section{References}

Arnqvist G, Daniclsson I (1999) Postmating sexual selection: the effects of male body size and recovery period on paternity and egg production rate in a water strider. Behav Ecol $10,358-365$.

Bissoondath CJ, Wiklund C (1996) Effect of male mating history and body size on ejaculate mass and quality in two polyandrous butterflies Pieris napi and Pieris rapae (Lepidoptera: Pieridae). Funct Ecol 10, 457-464.

Boggs CL (1990) A general model of the role of male donated nutrients in female insects reproduction. Am Nat 136, 598-617.

Cook PA, Wedell N (1996) Ejculate dynamics in butterflies: a strategy for maximizing fertilization success. Proc R Soc Lond B 263, 1047-1051.

Damiens D, Boivin G (2006) Why do sperm-depleted parasitoid males continue to mate. Behav Ecol 17, 138-143.

Eady PE (1995) Why do male Callosobruchus maculatus beetles inseminate so many sperm. Behav Ecol Sociobiol 36, 25-32.

Engqvist L, Sauer KP (2003) Determinants of sperm transfer in the scorpionfly Panorpa cognate: male variation, female condition and copulation duration. J Evo Biol 16, 11961204.

Fischer K, Zimmer K, Wedell N (2009) Correlated responses to selection on female egg size and male reproductive traits in a butterfly. Evol Eco 23, 389-402.

Flint HM, Kressin EL (1969) Transfer of sperms by irradiated Heliothis virescens (Lepidoptera: Noctuidae) and relationship to fecundity. Can Ento 101, 500-507.

Fox CW, Mclennan LA, Mousseau TA (1995a) Male body size affects female lifetime reproductive success in a seed beetle. Anim Behav 50, 281-284.

Fox CW, Hichman DL, Raleigh EL, Mousseau TA (1995b) Paternal investment in a seed beetle (Coleoptera: Bruchidae): influence of male size, age, and mating history. Ann Entomol Soc Am 88, 101-103.

Gage MJG (1998) Influence of sex, size and symmetry on ejaculate expenditure in a moth. Behav Ecol 9, 592-597.

Gage AR, Barnard CJ (1996) Male crickets increase sperm number in relation to competition and female size. Behav Ecol Sociobiol 38, 349-353.

Gillott C (2003) Male accessory gland secretions: modulators of female reproductive physiology and behavior. Annu Rev Entomol 48, 163-184.

Gwynne DT (1984) Sexual selection and sexual differences in Mormon crickets (Orthoptera, Teggigoniidae, Anabrus simplex). Evolution 38, 1011-1022.

Karlsson B (1998) Nuptial gifts, resource budgets, and reproductive output in a polyandrous butterfly. Ecology 79, 29312940.

Lauer MJ (1996) Effect of sperm depletion and starvation on female mating behavior in the water strider, Aquarius remigis. Behav Ecol Sociobiol 38, 89-96.

Lewis SM (2004) Multiple mating and repeated copulations: effects on male reproductive success in red flour beetles. Anim Behav 67, 799-804.

Lewis Z, Wedell N (2007) Effects of adult feeding on male mating behavior in the butterfly, Bicyclus anynana (Lepidoptera: Nymphalidae). J Insect Behav 20, 201-213.

Mallard ST, Barnard CJ (2003) Competition, fluctuating asymmetry and sperm transfer in male gryllid crickets (Gryllus bimaculatus and Gryllodes sigillatus). Behav Ecol Sociobiol 53, 190-197.

Moore PJ, Harris EW, Montrose TW, Levin D, Moore AJ (2004) Constraints on evolution and postcopulatory sexual selection: trade-offs among ejaculate characteristics. Evolution 58, 1773-1780.

Ofuya TI (1995) Multiple mating and its consequences in male of Callosobruchus maculatus (F.) (Coleoptera: Bruchidae). J Stored Prod Res 31, 71-75.

Rath SS (2000) Survival probability and fertility in male moths of Antheraea mylitta D. (Lepidoptera: Saturniidae) during aging. Int J Wild Silkmoth \& Silk 5, 39-42.

Rath SS, Prasad BC, Thangavelu K (2002) Age related mating schedule in Antheraea mylitta- A strategic approach to increase seed production; in Advances in Indian sericulture research. Dandin SB, Gupta VP (eds.), pp. 412-417, Central Sericultural Research and Training Institute, Mysore, India.

Rath SS, Sinha BRRP, Sinha SS (1997) Age specific changes in reproductive potential and longevity in female moths of Antheraea mylitta D. (Lepidoptera: Saturniidae). Indian J Seric 36, 39-42.

Rath SS, Narian R, Singh MK, Suryanaryana N (2007) Effect of mating delay and mating duration on reproductive performance of Antheraea mylitta. Int J Indust Entomol 14, 113119.

Reinhold K, Kurtz J, Engqvist L (2002) Cryptic male choice: sperm allocation strategies when female quality varies. J Evol Biol 15, 201-209.

Rönn JL, Katvala M, Arnqvist G (2008) Interspecific variation in ejaculate variation and associated effects on female fitness in seed beetles. J Evol Biol 21, 461-470.

Savalli UM, Fox CW (1998) Genetic variation in paternal investment in a seed beetle. Anim Behav 56, 953-961. 
Savalli UM, Fox CW (1999a) The effect of male mating history on paternal investment, fecundity and female remating in seed beetle Callosobruchus maculatus. Funct Ecol 13, 169-177.

Savalli UM, Fox CW (1999b) The effect of male size, age, and mating behavior on sexual selection in seed beetle Callosobruchus maculatus. Ethol Ecol Evol 11, 49-60.

Simmons LW, Craig M, Llorens T, Schinzig M, Hoskens D (1993) Bushcricket spermatophore vary in accord with sperm competition and parental investment theory. Proc R Soc Lond B 251, 183-186.

Sokal RR, Rohlf FJ (1995) Biometry. Freeman, New York.

Torres-Vila LM, Jennions MD (2005) Male mating history and female fecundity in the Lepidoptera: do male virgins make better partners. Behav Ecol Sociobiol 57, 318-326.

Vahed K (1998) The function of nuptial feeding in insectsreview of empirical studies. Biol Rev 73, 43-78.

Vahed K (2006) Larger ejaculate volumes are associated with a lower degree of polyandry across bushcricket texa. Proc R Soc B 273, 2387-2394.

Wedell N (1992) Protandry and mate assessment in the wart biter Decticus verrucivorus (Orthoptera: Tettigoniidae). Behav Ecol Sociobiol 31, 301-308.

Wedell N, Cook PA (1999) Strategic sperm allocation in the small white butterfly Pieris rapae (Lepidopteraa: Pieridae). Funct Ecol 13, 85-93.

Wedell N, Gage MJG, Parker GA (2002) Sperm competition, male prudence and sperm-limited females. Trends Ecol Evol 17, 313-320.

Wightman JA (1978) The ecology of Callosobruchus analis (Coleoptera: Bruchine): energetics and energy reserves of the adults. J Anim Ecol 47, 132-142.

Wiklund C, Kaitala A (1995) Sexual selection for large male in a polyandrous butterfly: the effect of body size on male versus female reproductive success in Pieris napi. Behav Ecol 6, 6-13. 